\title{
Corrosive-Abrasive Wear Induced by Soot in Boundary Lubrication Regime
}

\author{
F. Motamen Salehi ${ }^{1}$ D. N. Khaemba ${ }^{1}$ A. Morina ${ }^{1} \cdot$ A. Neville $^{1}$
}

Received: 17 February 2016/ Accepted: 6 June 2016/Published online: 17 June 2016

(C) The Author(s) 2016. This article is published with open access at Springerlink.com

\begin{abstract}
Soot is known to induce high wear in engine components. The mechanism by which soot induces wear is not well understood. Although several mechanisms have been suggested, there is still no consensus. This study aims to investigate the most likely mechanism responsible for soot-induced wear in the boundary lubrication regime. Results from this study have shown that previously suggested mechanisms such as abrasion and additive adsorption do not fully explain the high wear observed when soot is present. Based on the results obtained from tests conducted at varying temperature and soot levels, it has been proven that the corrosive-abrasive mechanism was responsible for high wear that occurred in boundary lubrication conditions.
\end{abstract}

Keywords Soot - Wear · Corrosive-abrasive wear . Engine oil · Raman spectroscopy

\section{Introduction}

In recent years, diesel engines have become more popular due to their higher fuel efficiency and lower running costs compared to gasoline engines. As emissions regulations have also become stricter, there is an increasing demand for reduction in nitrogen oxide (NOx) emissions from engines [1]. Exhaust gas recirculation (EGR) is believed to be the most effective means of reducing NOx emissions in diesel engines. However, the use of EGR system in diesel

F. Motamen Salehi

mn11fms@leeds.ac.uk

1 Institute of Functional Surfaces (IFS), University of Leeds, Leeds LS2 9JT, UK engines results in poor combustion performance and increase in particulate matter. The particulate matter emissions in diesel engines are about 50-80 times greater than emissions from spark-ignition engines. High amounts of particulate matter lead to increased wear of engine components [2]. Furthermore, because combustion products are recirculated back to the engine in the EGR system, oil contamination occurs [3].

Black carbonaceous soot forms due to the incomplete combustion of hydrocarbons during the combustion process. Soot exists in all in-service diesel engine oils. It reaches the engine by various means of blow-by during engine operation. The soot particles are either exhausted into the atmosphere or adsorbed by the lubricant. Soot in oil is one of the major causes of wear in engine components $[3,4]$. The mechanism by which soot causes wear has been a subject of interest to many researchers. So far, several mechanisms discussed below have been proposed.

\subsection{Competitive Adsorption}

It has been suggested that soot competes with antiwear additives in adsorbing on surfaces. The adsorption of soot on the surface prevents the adsorption of antiwear additives and their subsequent decomposition to form antiwear films [5]. It is believed that soot could restrict the amount of additives reaching the contact area. It has also been suggested that the adsorption of soot on surfaces can limit the amount of oxygen reaching the contact surface resulting in the formation of $\mathrm{FeO}$ oxide instead of $\mathrm{Fe}_{3} \mathrm{O}_{4}$ [6]. Unlike $\mathrm{Fe}_{3} \mathrm{O}_{4}, \mathrm{FeO}$ does not have antiwear properties and as such promotes wear of the metallic surfaces in contact. 


\subsection{Additive Adsorption by Soot}

It has also been suggested that soot adsorbs antiwear additives in the oil phase reducing the concentration of the additives in the lubricant. Consequently, less antiwear additives adsorb at the contact interface to form antiwear films [7].

\subsection{Oil Starvation}

In some studies, it has been suggested that soot in the oil can accumulate at the contact inlet restricting oil supply to the contact [8]. The absence of a lubricant film at the contact results in high wear due to the metal-on-metal contact.

\subsection{Abrasion}

This is the most accepted mechanism. It is believed that soot enhances wear either through directly abrading the metallic parts of the engine [9-12] or by abrasion of antiwear tribofilms formed on the surfaces [13]. Removal of the antiwear tribofilm by soot exposes the underlying metallic surface to wear [14].

\subsection{Corrosive-Abrasive Wear}

Olomolehin et al. [13] reported that wear increased by 100-2000 times when phosphorus (P-) and sulphur (S)based antiwear and/or extreme pressure additives were added to a mineral base containing carbon black (commonly used surrogate for soot). In the mentioned study, it was concluded that the high wear observed when P- and S-based additives were present was due to corrosiveabrasive mechanism. This mechanism has also been suggested in other previous studies $[10,12]$.

Although various wear mechanisms have been proposed, there is still no consensus on the mechanism responsible for high wear when soot is present in oil. This necessitates further fundamental studies on the underlying wear mechanism. Besides causing high wear, the presence of soot in oil can also affect friction. In comparison with the effect of soot on wear, there are less studies on the effect of soot on friction $[15,16]$. In some studies, it has been shown that the presence of soot may act as a friction modifier [15]. This is because soot has a similar structure to graphite which is a well-known solid lubricant. Other studies have reported that the presence of soot can lead to an increase in friction [4, 16-18]. The conflicting reports on the influence of soot on friction necessitate further investigation.

The main objective of this paper was to investigate the mechanism by which soot-induced wear occurs in fully formulated engine oils under boundary lubricated conditions. Tribological tests were conducted using steel-onsteel contacts under unidirectional linear sliding conditions.

\section{Experimental Methodology}

\subsection{Materials}

A commercially available fully formulated oil (FFO) was used with the viscosity grade of 5W-30. Inductively coupled plasma (ICP) analysis of the fresh oil revealed that it was composed of calcium, zinc, magnesium, boron, molybdenum, silicon, and sodium. A commercially available Monarch 120 carbon black (hereafter denoted CB) was obtained from Cabot Corporation. The $\mathrm{CB}$ was used to simulate engine soot. Figure 1 shows an optical image of the CB used in this study. The size of soot particles from diesel combustion is around $40-45 \mathrm{~nm}$ diameter $[13,18]$. The individual $\mathrm{CB}$ particles used in this study are approximately $50 \mathrm{~nm}$ diameter. The rounded particles are agglomerates of smaller particles and are $100 \mathrm{~nm}$ in size. In terms of hardness, it is difficult to measure the precise hardness of soot and CB as it varies significantly. Carraher [19] reported that CB is very soft with a hardness of ca 1 on the Mohs scale. However, Jao [20], using a different measurement method, suggested a higher value between 8 and $10 \mathrm{GPa}$.

In the literature, there have been concerns regarding the use of CB to simulate soot. These concerns mainly question the similarity between CB particles and soot obtained from diesel engines since they are formed as a result of different processes. Unlike soot, which is an unwanted by-product of combustion, $\mathrm{CB}$ is produced under controlled conditions [21]. There are two main obstacles to use soot in

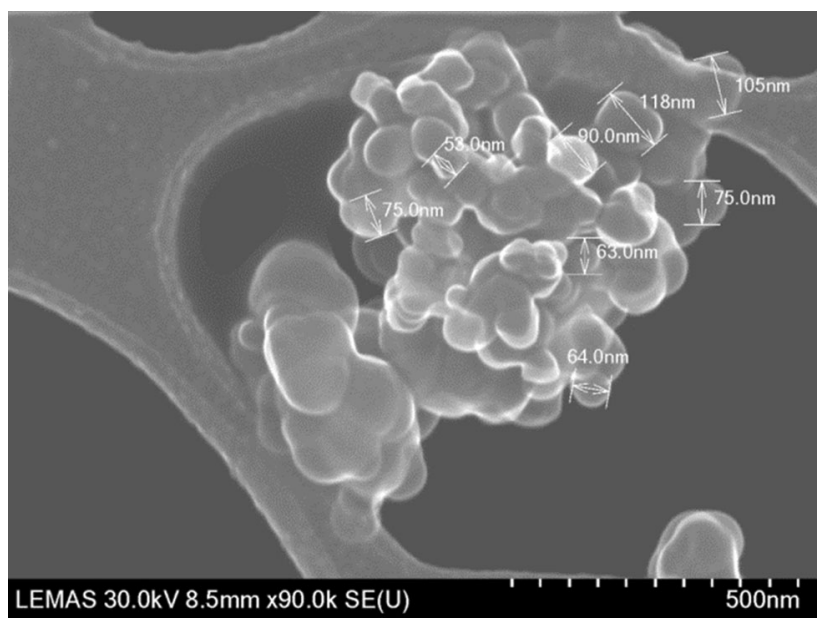

Fig. 1 STEM micrograph of carbon black particles 
experimental studies. Firstly, it is very hard and timeconsuming to extract soot from used engine oil. Secondly, the quality of soot extracted from used oils varies greatly with regard to the level of carbon graphitisation, size, chemical composition, and dispersion properties [22]. Thus, results obtained from tests conducted with soot cannot be easily compared with other reported literature. To overcome this problem, the use of $\mathrm{CB}$ has been adopted in lieu of soot in several reported studies. This has allowed repeatable experiments to be carried out and reliable data to be obtained $[4,13]$. It should be noted that there has been no attempt to investigate the differences between soot and CB in this study as this is not the focus of the study. Results obtained in this study were compared to other reported studies where $\mathrm{CB}$ was used and not soot.

EDX analysis conducted on the CB particles revealed that the particles were composed of carbon (91 wt $\%$ ), oxygen $(8.5 \mathrm{wt} \%)$, and sulphur $(0.5 \mathrm{wt} \%)$. It has been reported that soot contains $90 \%$ of carbon, $4 \%$ of oxygen, $3 \%$ of hydrogen, and trace amounts of nitrogen and sulphur [23]. The elemental analysis of the $\mathrm{CB}$ particles shows that the carbon content of the $\mathrm{CB}$ particles is similar to that of soot from actual engines.

In this study, CB was added into the FFO at mass percentages of $0,1,2,3,4$, and $5 \mathrm{wt} \%$. These are reasonable $\mathrm{CB}$ levels as the level of soot in engine varies in oil during use from 1-8 wt\% [13]. CB was mixed in FFO in an ultrasonic bath for $30 \mathrm{~min}$ prior to tests in order to uniformly distribute the $\mathrm{CB}$ in the oil. Figure 2 shows the viscosity of the oils at different $\mathrm{CB}$ levels. It can be seen that at ambient temperature $\left(20{ }^{\circ} \mathrm{C}\right)$, the viscosity of the oils increased slightly with increase in CB levels. Overall, the viscosity of the oils decreased with increase in temperature to 40 and $100{ }^{\circ} \mathrm{C}$. At higher temperatures, there was no significant difference in the viscosity of the oils

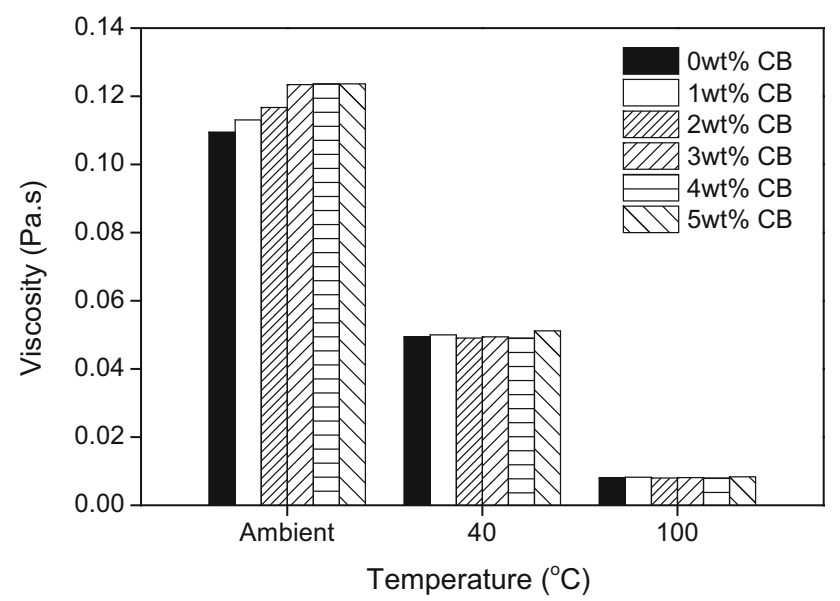

Fig. 2 Viscosity of oils at varying $\mathrm{CB}$ levels as a function of temperature with increase in CB levels. Additional tests were conducted using group III mineral oil hereafter referred to as base oil (BO). In some tests conducted with BO and CB, 2 wt\% of Triton X-100, a commercially available dispersant (disp), was added to the oil. This was done in order to keep the $\mathrm{CB}$ particles well dispersed in the oil.

\subsection{Tribotests}

All experiments were conducted using a high-speed ballon-disc tribometer test rig which operates under unidirectional linear sliding conditions. Figure 3 shows the schematic representation of the contact in the test set-up. The ball was fixed in the contact while the disc was rotated. The test conditions used are shown in Table 1. These test conditions simulate the contact in a vane pump. Table 2 shows the initial lambda $(\lambda)$ values for oils with varying $\mathrm{CB}$ levels at both 40 and $100{ }^{\circ} \mathrm{C}$. From the initial lambda values, it can be seen that at the beginning, all tests were conducted in boundary lubrication regime.

Table 3 shows the chemical composition of discs and balls used in this study. The balls were $6.35 \mathrm{~mm}$ in diameter and were made of AISI 52,100 high chromium alloy. The discs were made of AISI 1050 carbon steel. The inside and outside diameters of the discs were 25 and $42 \mathrm{~mm}$, respectively. The samples were cleaned prior to the test with acetone for 10 min using an ultrasonic bath. All tests were conducted at least two times to check for repeatability.

\subsection{Post-test Analysis}

\subsubsection{Wear Analysis}

Optical microscopy and white light interferometry were used to obtain images of wear scars after tribological tests in order to asses wear. Optical images were used to determine wear scar diameters on the balls. Three-dimensional images obtained using white light interferometry

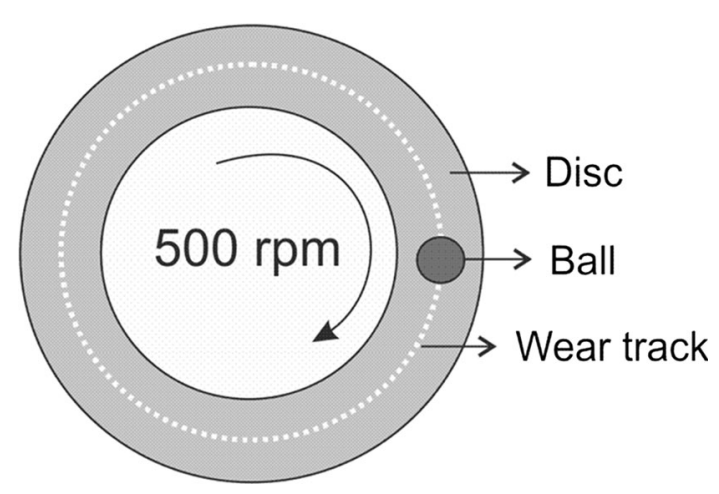

Fig. 3 Schematic diagram of the ball-on-disc set-up 
were used to calculate wear volumes on the balls. As the initial roughness of the disc was high, it was difficult to measure wear volumes on the discs. Wear volume of the ball $\left(\mathrm{V}_{\text {wear-ball }}\right)$ was calculated using Eq. (1).

$V_{\text {wear-ball }}=\frac{\pi h}{6}\left(3 r^{2}+h^{2}\right), \quad h=R-\sqrt{R^{2}-r^{2}}$

where $h$ is the height of wear of the ball, $r$ is the radius of wear scar, $R$ is the radius of the ball.

\subsubsection{Surface Chemical Characterisation}

Chemical characterisation of generated wear scars after testing was conducted using EDX analysis and Raman spectroscopy. EDX analysis was employed to study the elemental composition of surface films formed on the wear scars. EDX probes more than $1 \mu \mathrm{m}$ in depth; therefore, the result is from both the metal substrate and tribofilm. Four different positions were selected for the measurement to check the uniformity of element distribution. Raman analysis was also carried out using a Renishaw InVia spectrometer (UK). All spectra reported in this study were obtained with 488 -nm wavelength laser at room temperature. Peaks were analysed using the Renishaw WiRE

Table 1 Ball-on-disc test conditions

\begin{tabular}{ll}
\hline Motion & Pure sliding \\
\hline Oil & Synthetic engine oil $5 \mathrm{~W} 30$ \\
Temperature & $40{ }^{\circ} \mathrm{C}, 100{ }^{\circ} \mathrm{C}$ \\
Sliding speed & $500 \mathrm{rpm}(0.78 \mathrm{~m} / \mathrm{s})$ \\
Test duration & $120 \mathrm{~min}$ \\
Initial contact pressure & Max $0.83 \mathrm{GPa}$ \\
Roughness, Ra $(\mathrm{nm})$ & Ball $=13 ;$ Disc $=112$ \\
\hline
\end{tabular}

Table 2 Lambda ratio for oils containing various levels of contamination

\begin{tabular}{lll}
\hline CB level in oil (wt\%) & $\lambda$ at $40{ }^{\circ} \mathrm{C}$ & $\lambda$ at $100{ }^{\circ} \mathrm{C}$ \\
\hline 0 & 0.68 & 0.19 \\
1 & 0.69 & 0.20 \\
2 & 0.68 & 0.19 \\
3 & 0.68 & 0.20 \\
4 & 0.68 & 0.19 \\
5 & 0.70 & 0.20 \\
\hline
\end{tabular}

program. Raman analysis was conducted on at least 10 different positions on each sample to check for uniformity in chemical composition of the wear scars.

\section{Results and Discussions}

\subsection{Friction Results}

The average friction coefficient values for the last $30 \mathrm{~min}$ of the tests are shown in Fig. 4. It can be seen that FFO showed the highest friction coefficient at both temperatures. At both 40 and $100{ }^{\circ} \mathrm{C}$, there was a sharp decrease in friction, about $50 \%$, when $1 \mathrm{wt} \% \mathrm{CB}$ was added to the oil. The friction further decreased when the level of $\mathrm{CB}$ was increased to $5 \mathrm{wt} \%$.

In previous studies, there have been contradictory reports on the influence of soot on friction performance. Friction results obtained in previous studies are summarised in Table 4. The varying friction behaviour observed in the various reports can be attributed to differences in test conditions such as sliding contact configuration, lubricant type, and temperature. The type of FFO oil can affect the friction performance in the presence of CB. Liu et al. [15] reported that two oils with varying chemical compositions showed completely different friction behaviour when $3 \mathrm{wt} \% \mathrm{CB}$ was added. In one oil,

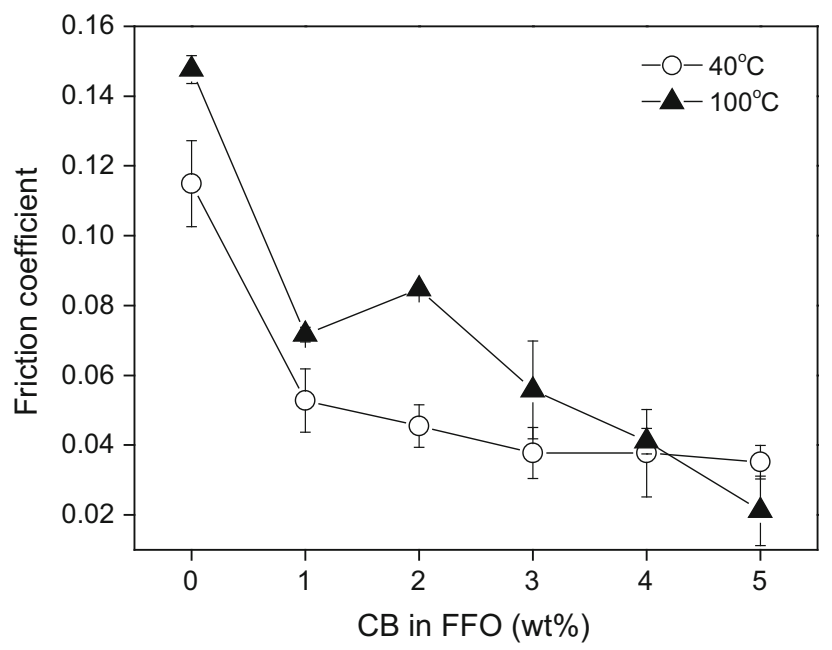

Fig. 4 Friction as a function of soot content in FFO. The friction values are an average of friction coefficient during the last $30 \mathrm{~min}$ of tests
Table 3 Chemical composition of samples

\begin{tabular}{lllllll}
\hline & Material & $\mathrm{C}(\%)$ & $\mathrm{Mn}$ & $\mathrm{Si}$ & $\mathrm{P}$ & $\mathrm{S}$ \\
\hline Ball & AISI 52,100 & $0.95-1.10$ & $1.10 \% \max$ & $0.10-0.35 \%$ & $0.05 \% \max$ & $0.05 \% \max$ \\
Disc & AISI 1050 & $0.48-0.55$ & $0.60-0.90 \%$ & N/A & $0.04 \% \max$ & $0.05 \% \max$ \\
\hline
\end{tabular}


Table 4 Summary of results obtained from previous studies

\begin{tabular}{|c|c|c|c|c|c|}
\hline Tribometer type & Lubricant & $\mathrm{CB}(\mathrm{wt} \%)$ & Friction coefficient $(\mu)$ & Test conditions & Reference \\
\hline Four ball & $15 \mathrm{~W}-40$ & $0-8$ & $0.01-0.05$ & $30 \mathrm{~min}, 25^{\circ} \mathrm{C}, 100-1200 \mathrm{rpm}, 2.51 \mathrm{GPa}$, & {$[4]$} \\
\hline Pin on disc & $\begin{array}{l}\text { Model oil }+ \text { additive } \\
\text { package }\end{array}$ & $0-10$ & -0.14 & $18-23{ }^{\circ} \mathrm{C}, 5 \mathrm{~m} / \mathrm{s}, 2 \mathrm{GPa}$ & {$[18]$} \\
\hline $\begin{array}{l}\text { Reciprocating } \\
\text { rig }\end{array}$ & $10 \mathrm{~W}-40$ & $0-5$ & 0.075 & $20 \mathrm{~min}, 0.21 \mathrm{~m} / \mathrm{s}$ & {$[16]$} \\
\hline SRV & $10 \mathrm{~W}-30$ & $0-4$ & $0.06-0.15$ & $30 \min , 40-130{ }^{\circ} \mathrm{C}$ & [15] \\
\hline Pin on disc & - & $0-10$ & $0.11-0.13$ & $60 \mathrm{~min}, 28{ }^{\circ} \mathrm{C}, 5 \mathrm{~m} / \mathrm{s}, 2 \mathrm{GPa}$, & {$[24]$} \\
\hline Pin on disc & $5 \mathrm{~W}-30$ & $0-5$ & $0.02-0.14$ & $120 \mathrm{~min}, 40-100{ }^{\circ} \mathrm{C}, 0.78 \mathrm{~m} / \mathrm{s}, 0.83 \mathrm{GPa}$ & This study \\
\hline
\end{tabular}

there was friction reduction (0.06), while in the other, there was no friction reduction (0.12). In tests conducted using a four-ball machine, exceptionally low friction values (0.01-0.02) were reported for tests conducted with FFO, without the addition of CB [4]. Such low friction values for FFO indicate the presence of an efficient friction modifier in the lubricant. This friction modifier was probably absent in other reported studies where FFO was used. Liu et al. [15] reported that the friction for oils containing CB increased with increase in temperature.

In some studies, it has been reported that addition of CB to fully formulated oils increased the viscosity of the lubricants [16]. Those findings are however in conflict with other studies where viscosity of fully formulated oils did not change when CB was added [4]. In the current study, the viscosity of the lubricant did not significantly change at different CB levels. Thus, it was concluded that the friction behaviour observed in FFO with the $\mathrm{CB}$ could not be sufficiently explained by changes in the viscosity of the oil.

In this study, a rapid drop in friction was observed when $\mathrm{CB}$ was added to FFO. This suggests that the presence of $\mathrm{CB}$ in the oil was somehow responsible for the low friction observed. Studies have shown that CB is only capable of providing low friction when it is uniformly dispersed in the oil using dispersants. Good dispersion of CB in oil enables $\mathrm{CB}$ to be entrained within the contact where it acts as a solid lubricant. In the absence of a dispersant, CB agglomerates at the inlet of the tribocontact causing lubricant starvation which results in high friction [18]. It is thus believed that the low friction observed in this study when CB was added to the oil was due to good dispersion since the oil contained dispersants. At the contact interface, $\mathrm{CB}$ was able to act as a friction modifier since it has a similar structure to that of graphite, a well-known solid lubricant.

It should be highlighted that the sliding contact used to carry out tests can also affect the friction observed. This aspect was confirmed by the authors by conducting experiments with $\mathrm{FFO}+\mathrm{CB}$ in a reciprocating tribometer.

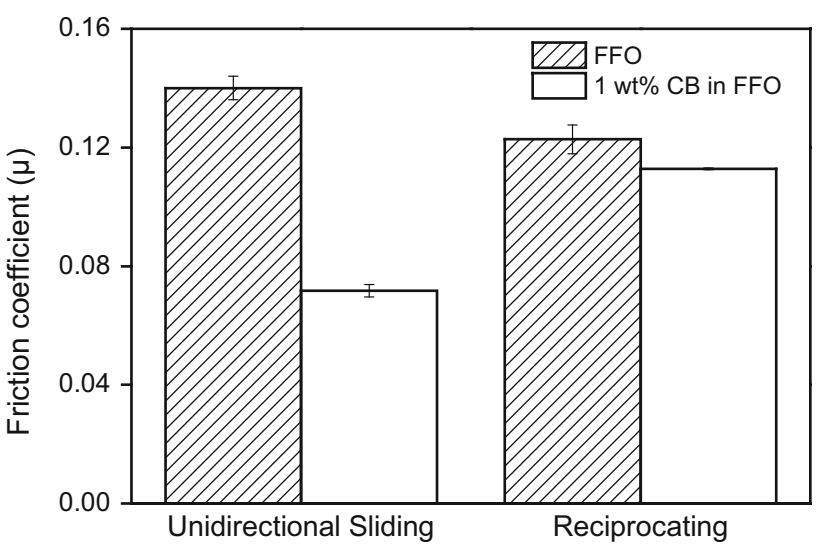

Fig. 5 Friction comparison at different sliding configurations

Figure 5 compares friction results obtained under unidirectional sliding and reciprocating sliding. It was observed that while CB in FFO provided friction reduction in unidirectional linear sliding conditions, similar friction reduction was not observed in reciprocating sliding conditions. One probable reason for this observation could be that $\mathrm{CB}$ entrainment within the sliding interface was hindered in reciprocating contacts. This is likely to occur if the sliding frequency is too high such that the lubricant displaced from the contact during the forward stroke is not fully replaced during the reversal stroke. These results can also explain the conflicting friction values reported in previous studies when different sliding configurations were used.

\subsection{Wear Results}

Figure 6 shows the wear volume loss on the ball after tests at 40 and $100{ }^{\circ} \mathrm{C}$. The lowest wear was observed when no $\mathrm{CB}$ was present in the FFO. In tests without $\mathrm{CB}$, wear was lower at $100{ }^{\circ} \mathrm{C}$ than at $40{ }^{\circ} \mathrm{C}$. Since the viscosity of the FFO (without CB) was higher at $40{ }^{\circ} \mathrm{C}$ than at $100{ }^{\circ} \mathrm{C}$ (as shown in Fig. 2), it is expected that the lubricant film 


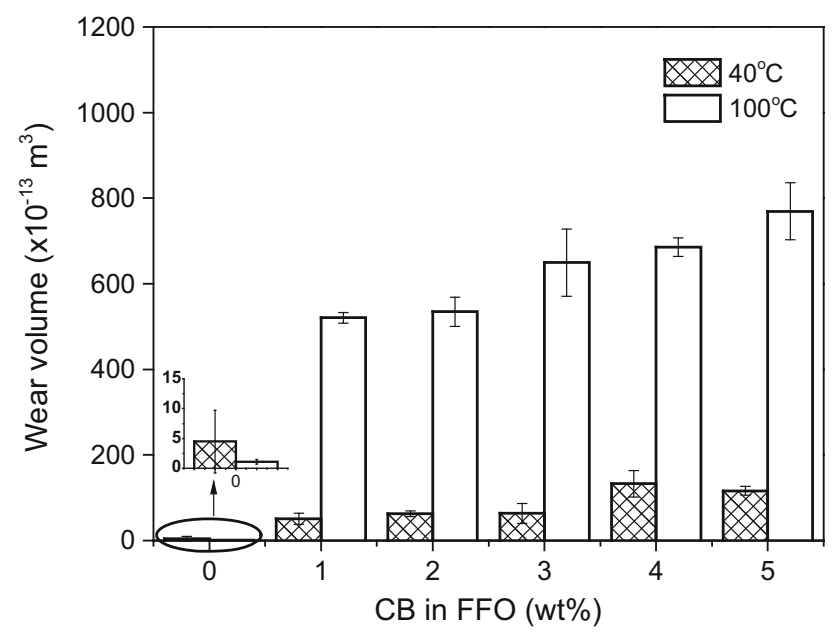

Fig. 6 Wear volume loss on balls at varying CB content in FFO for tests conducted at 40 and $100{ }^{\circ} \mathrm{C}$

thickness would be thicker at $40{ }^{\circ} \mathrm{C}$ than at $100{ }^{\circ} \mathrm{C}$. Due to the thinner lubricant film at the higher temperature, there is more asperity-to-asperity contact which would promote wear. However, more wear was observed at $40{ }^{\circ} \mathrm{C}$ than at $100{ }^{\circ} \mathrm{C}$ despite the lubricant film being thicker at the lower temperature. A reasonable explanation for the wear observation can be explained by considering the formation of more effective antiwear films at higher temperatures which was promoted by the solid-to-solid contact. The formation of the antiwear films in the presence of FFO is discussed in detail in Sect. 3.3.

The addition of CB to FFO resulted in an increase in the wear volume loss. Higher wear was observed at $100{ }^{\circ} \mathrm{C}$ than at $40{ }^{\circ} \mathrm{C}$. Figure 7 shows optical images of wear scars generated on the balls at varying CB levels and temperatures. It was observed that the wear scar diameter increased significantly with the addition of $\mathrm{CB}$ in the oil. At similar $\mathrm{CB}$ content levels, the wear scar diameters were larger at $100{ }^{\circ} \mathrm{C}$ than at $40{ }^{\circ} \mathrm{C}$. The increase in wear with $\mathrm{CB}$ level has also been reported in previous studies in tests conducted with FFO $[16,18]$ as well as in tests conducted with model oils containing P- and S-based antiwear and extreme pressure additives [13].

\subsection{Surface Characterisation}

Figure 8 shows Raman spectra obtained from tribopair wear scars after tests with FFO without CB. At both 40 and $100{ }^{\circ} \mathrm{C}$, it was observed that the wear scars were composed of phosphates as can be seen by the broad peak at $900-1100 \mathrm{~cm}^{-1}$ [25]. The presence of phosphate films in the wear scars was due to the decomposition of ZDDP additive which was present in the FFO. The Raman spectra also showed the presence of iron sulphide (FeS) evidenced by the broad peak at $200-400 \mathrm{~cm}^{-1}$. The broad peak in the region of $700-800 \mathrm{~cm}^{-1}$ was assigned to the presence of calcium hydroxide $[26,27]$ while the peak at $670 \mathrm{~cm}^{-1}$ was assigned to $\mathrm{Fe}_{3} \mathrm{O}_{4}$. Broad peaks belonging to amorphous carbon were also observed at 1373 and $1575 \mathrm{~cm}^{-1}$ [28]. The presence of $\mathrm{Zn}, \mathrm{P}$, and $\mathrm{S}$ in the wear scars was also confirmed by EDX analysis. In previous studies, the formation of ZDDP tribofilms composed of phosphate has been reported to provide wear protection [29]. The presence of the ZDDP tribofilms within wear scars in test with FFO thus explains the low wear as observed in Fig. 6.

In a previous study by Ardian and Anne [30] where tests were conducted with mineral oil containing only ZDDP, it was observed that wear decreased with increase in temperature in agreement with wear results obtained from this study where FFO was used.

This suggests that the effect of temperature on the wear performance of ZDDP is similar in both BO and FFO. It has been reported that the thickness of ZDDP antiwear tribofilms increases with increase in temperature [31]. With EDX analysis, it was observed that the amount of elements $\mathrm{Zn}, \mathrm{P}$, and $\mathrm{S}$ was higher at $100{ }^{\circ} \mathrm{C}$ than at $40{ }^{\circ} \mathrm{C}$. It is thus probable that in the absence of $\mathrm{CB}$, thicker antiwear films formed at the higher temperature were more effective in reducing wear than those at $40{ }^{\circ} \mathrm{C}$. This would explain the higher wear observed at $40{ }^{\circ} \mathrm{C}$ than at $100{ }^{\circ} \mathrm{C}$.

Figure 9 shows Raman spectra obtained from tribopair wear scars after tests with FFO containing $5 \mathrm{wt} \%$ CB. These spectra only showed the presence of $\mathrm{Ca}(\mathrm{OH})_{2}$ $\left(810 \mathrm{~cm}^{-1}\right), \mathrm{Fe}_{3} \mathrm{O}_{4}\left(670 \mathrm{~cm}^{-1}\right)$, and $\mathrm{FeS}\left(300 \mathrm{~cm}^{-1}\right)$ [25]. Phosphate peaks previously observed in tests with FFO were not observed. Phosphate compounds were also not detected by EDX analysis. As phosphate films are well known for their antiwear properties, the absence of the films would explain the high wear observed when $\mathrm{CB}$ was present. Possible reasons why phosphate films were not observed in tests conducted with $\mathrm{CB}$ could be as follows: (1) Phosphate films were removed by the CB as soon as they were formed, and (2) the formation of phosphate films was inhibited in the first place probably due to the adsorption of the additive by $\mathrm{CB}$ in the oil phase as has been previously suggested. The possibility of these two processes occurring at the contact interface is discussed in greater detail in Sect. 3.4.

\subsection{Wear Mechanisms}

\subsubsection{Abrasion of Antiwear Tribofilms and Steel Substrate}

As previously mentioned, the absence of antiwear films at the tribocontact in the presence of $\mathrm{CB}$ can be due to formed antiwear films being abraded by $\mathrm{CB}$ particles. It has been 


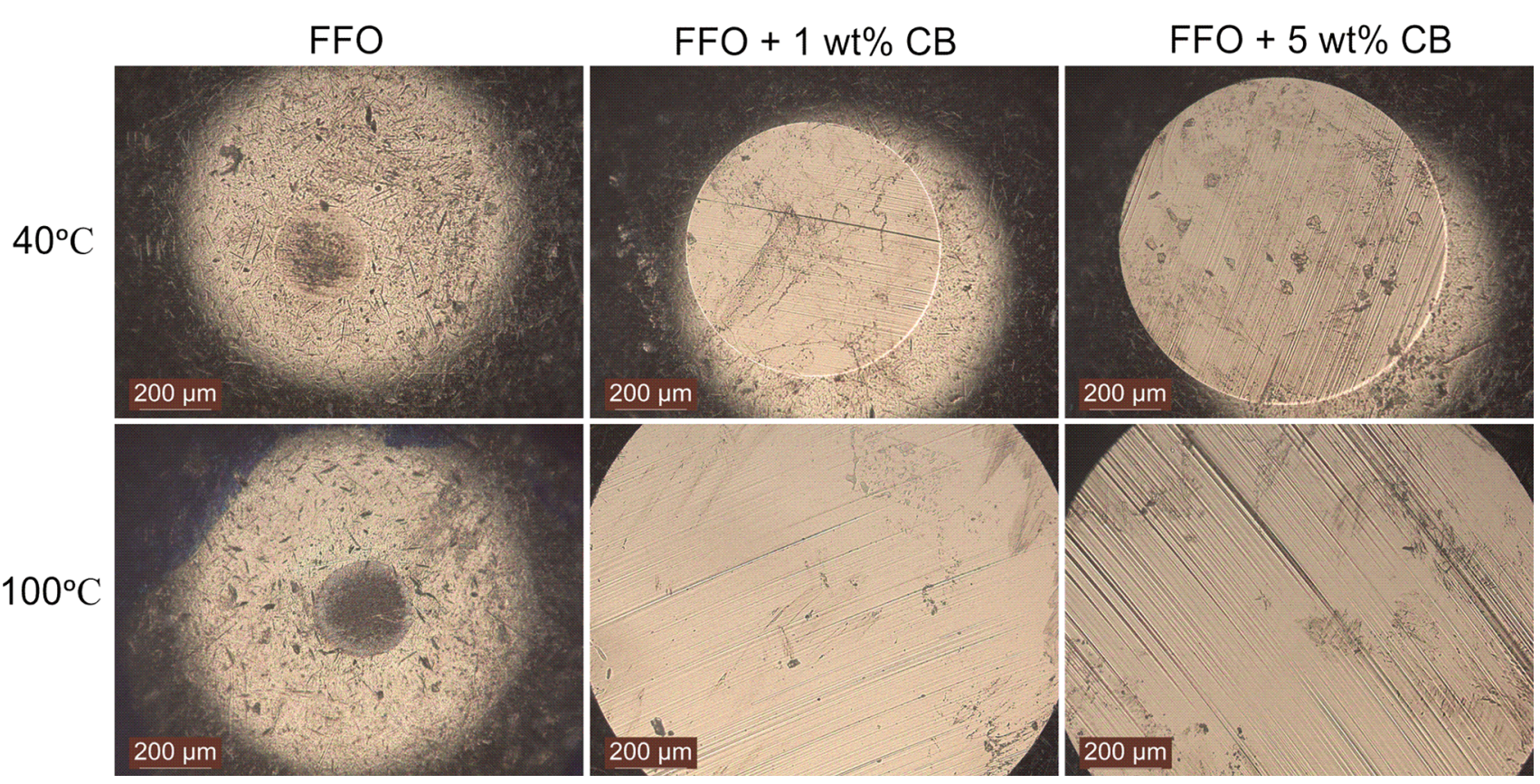

Fig. 7 Optical images of the wear scars formed on balls after tests with FFO, 1 and 5 wt $\%$ CB at 40 and $100{ }^{\circ} \mathrm{C}$
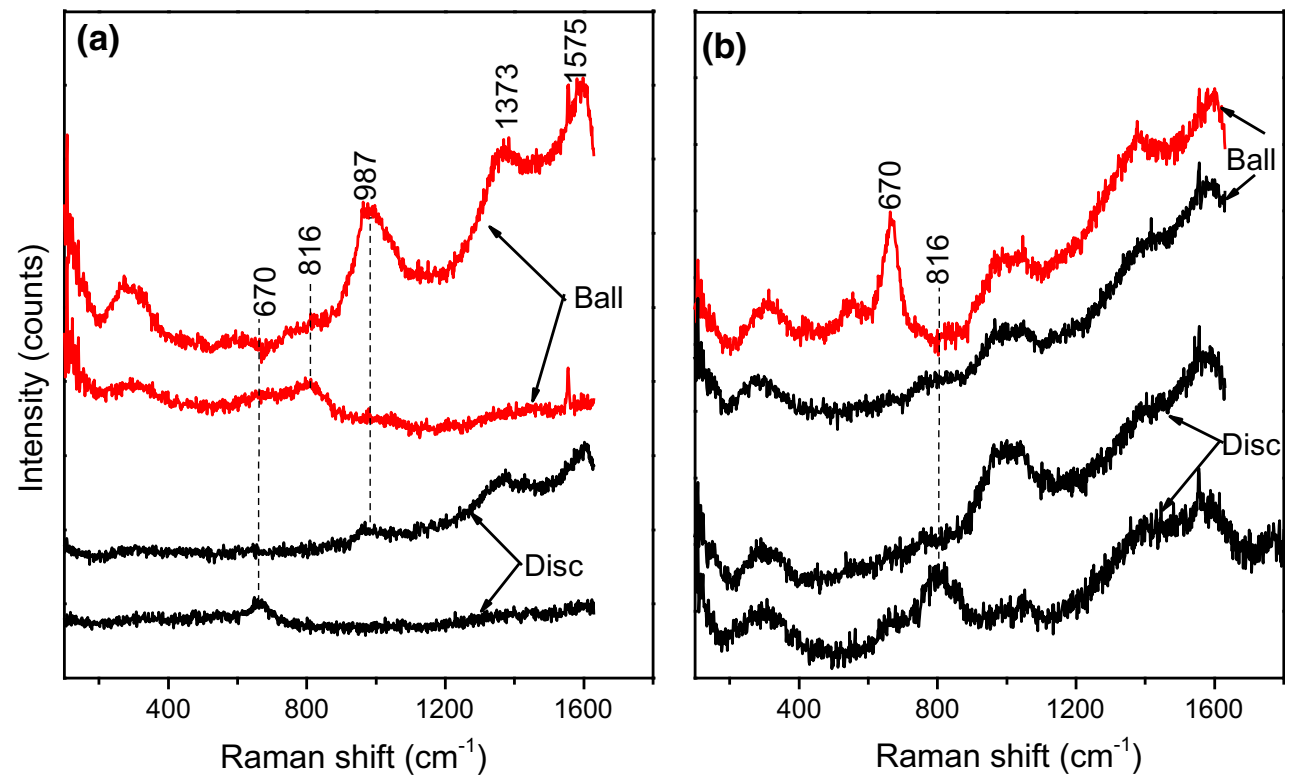

Fig. 8 Raman spectra obtained from different positions on tribopair samples after tests with $\mathrm{FFO}$ at a $40{ }^{\circ} \mathrm{C}$ and $\mathbf{b} 100{ }^{\circ} \mathrm{C}$

reported that ZDDP antiwear films are rapidly removed in the presence of soot [13]. In case the formed ZDDP tribofilm was removed from the contact by $\mathrm{CB}$ particles, the steel substrate would become prone to wear by CB particles due to the lack of protective tribofilm. To simulate the wear that would be generated on the steel substrate due to the presence of $\mathrm{CB}$, tests were conducted using $\mathrm{BO}$ containing $\mathrm{CB}$. As the $\mathrm{BO}$ did not contain any additives, the resulting wear would be due to abrasion by the $\mathrm{CB}$ particles. Tests were only conducted at $100{ }^{\circ} \mathrm{C}$ and $5 \mathrm{wt} \% \mathrm{CB}$ since the highest wear was observed at these conditions. The tests were conducted using test conditions as shown in Table 1. It should be noted that the viscosities of FFO and BO at $100{ }^{\circ} \mathrm{C}$ were 0.006 and 0.003 (Pas), respectively. After adding $5 \mathrm{wt} \%$ of $\mathrm{CB}$ to the oils, the viscosities of FFO and BO were 0.008 and 0.007 (Pas), respectively. 

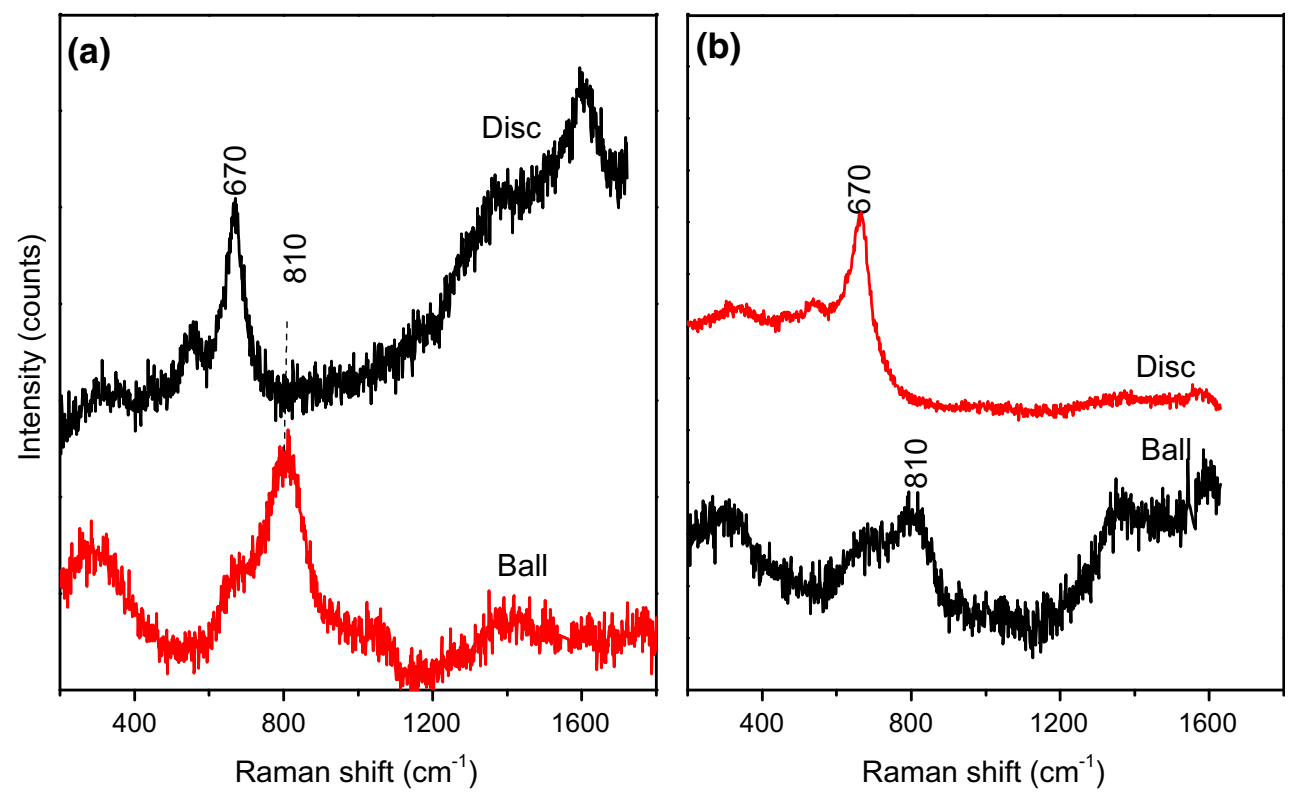

Fig. 9 Raman spectra of tribopair wear scars after tests with FFO containing 5 wt $\% \mathrm{CB}$ for tests conducted at a $40{ }^{\circ} \mathrm{C}$ and $\mathbf{b} 100{ }^{\circ} \mathrm{C}$

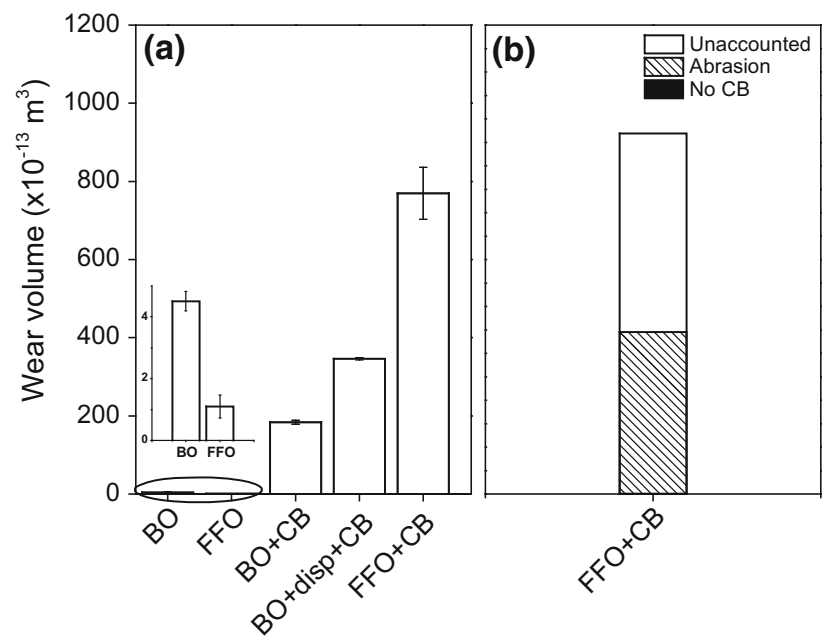

Fig. 10 a Wear results of BO and FFO with $5 \mathrm{wt} \%$ CB b proportion of wear accounted by abrasion in $\mathrm{FFO}+5 \mathrm{wt} \% \mathrm{CB}$. The black portion for No CB in (b) cannot be seen in the bar chart since the wear volume is very small in comparison with the overall wear volume. All tests were conducted at $100{ }^{\circ} \mathrm{C}$ for $2 \mathrm{~h}$

Boundary lubrication regime was achieved at these test conditions.

Figure 10a shows wear results obtained from tests with BO compared to those of FFO. In the absence of $\mathrm{CB}$, the wear was higher in tests with $\mathrm{BO}$ than with $\mathrm{FFO}$ as expected since no antiwear films were formed in tests with $\mathrm{BO}$. Addition of $\mathrm{CB}$ to the $\mathrm{BO}$ resulted in the wear volume loss increasing by $179 \times 10^{-13} \mathrm{~m}^{3}$. In tests with FFO, the wear volume loss increased by $768 \times 10^{-13} \mathrm{~m}^{3}$ when $\mathrm{CB}$ was added. The wear results in Fig. 10a are in agreement with those obtained by Olomolehin et al. [13] who observed that wear increased by more than 2000 times when ZDDP was added to model oils (mineral oil + dispersant) containing $5 \mathrm{wt} \% \mathrm{CB}$.

It should be highlighted that the BO did not contain any dispersant while the dispersant was present in FFO. There are some reports that suggest that the presence of dispersant can affect the wear behaviour of oils containing CB. The lack of a dispersant in BO could cause less CB particles go through the contact due to the agglomeration of $\mathrm{CB}$ particles resulting in the lower wear than $\mathrm{FFO}+\mathrm{CB}$ [13]. In order to investigate the effect of dispersant in CBcontaminated oil, tests were also conducted with $2 \mathrm{wt} \%$ dispersant in BO containing $5 \mathrm{wt} \% \mathrm{CB}$. Addition of $2 \mathrm{wt} \%$ dispersant in $\mathrm{BO}$ resulted in an increase in wear volume loss by $345 \times 10^{-13} \mathrm{~m}^{3}$, and this was a $48 \%$ increase compared to $\mathrm{BO}+5 \mathrm{wt} \% \mathrm{CB}$. These results thus show that wear increases in the presence of dispersants.

If $345 \times 10^{-13} \mathrm{~m}^{3}$ of the wear volume loss in tests with $\mathrm{FFO}+\mathrm{CB}$ is attributed to wear loss due to third-body abrasion by CB, it can be seen in Fig. 10b that there is still a large proportion of wear volume loss $\left(423 \times 10^{-13} \mathrm{~m}^{3}\right)$ that remains unaccounted for. If abrasion of the tribofilm and the steel substrate was the cause of the high wear observed in oils containing $\mathrm{CB}$, wear would have been similar in BO and FFO. However, from results in this present study, it can be seen that abrasion alone as a mechanism cannot explain the extremely high wear observed in oils containing antiwear additives. Also, these results indicate an antagonistic interaction between $\mathrm{CB}$ and oils containing antiwear additive ZDDP. 


\subsubsection{Additive Adsorption}

As previously suggested, the absence of antiwear phosphate films in tests with $\mathrm{FFO}+\mathrm{CB}$ can also be due to antiwear additives in the oil being adsorbed by $\mathrm{CB}$ [4]. To investigate antiwear additive adsorption by $\mathrm{CB}$ in $\mathrm{FFO}$, $5 \mathrm{wt} \%$ of CB was added to FFO and homogenously mixed in an ultrasonic bath for $30 \mathrm{~min}$. The oil was then heated on a hot plate at $100{ }^{\circ} \mathrm{C}$ for $2 \mathrm{~h}$ to allow additive adsorption to take place. The heated oils were allowed to cool down before being centrifuged at 12,000 rpm for one hour to separate CB particles from the oil. The resulting oil was then used in tribological tests. The tests were conducted at $100{ }^{\circ} \mathrm{C}$ using test conditions shown in Table 1 . Tests with such oils provide wear results after additive adsorption and also eliminate the effect of wear by $\mathrm{CB}$ abrasion. The heated and filtered oil sample is hereafter designated as $\mathrm{H} \& \mathrm{~F}$.

ICP analysis was conducted on fresh FFO (no CB) and $\mathrm{H} \& \mathrm{~F}$. Figure 11 shows the zinc concentration in fresh FFO and $H \& F$ sample. It can be seen that concentration of zinc in the oil reduced by approximately $55 \%$ after heating for $2 \mathrm{~h}$. These results show that a proportion of the additives was adsorbed by $\mathrm{CB}$ particles. In order to confirm additive adsorption by $\mathrm{CB}$ particles, EDX analysis was conducted on the $\mathrm{CB}$ particles that were filtered from the oils. As mentioned earlier in Sect. 2.1, the initial CB particles were mainly composed of carbon, oxygen, and a low level of sulphur. However, EDX analysis of the filtered CB particles revealed the presence phosphorus and zinc which are elements of ZDDP present in the FFO. Both ICP and EDX results confirmed that partial ZDDP adsorption did indeed occur.

Figure 12 shows wear results after tests with $\mathrm{H} \& \mathrm{~F}$ oil sample compared to FFO containing different levels of CB. It should be noted that not all of the $\mathrm{CB}$ particles were

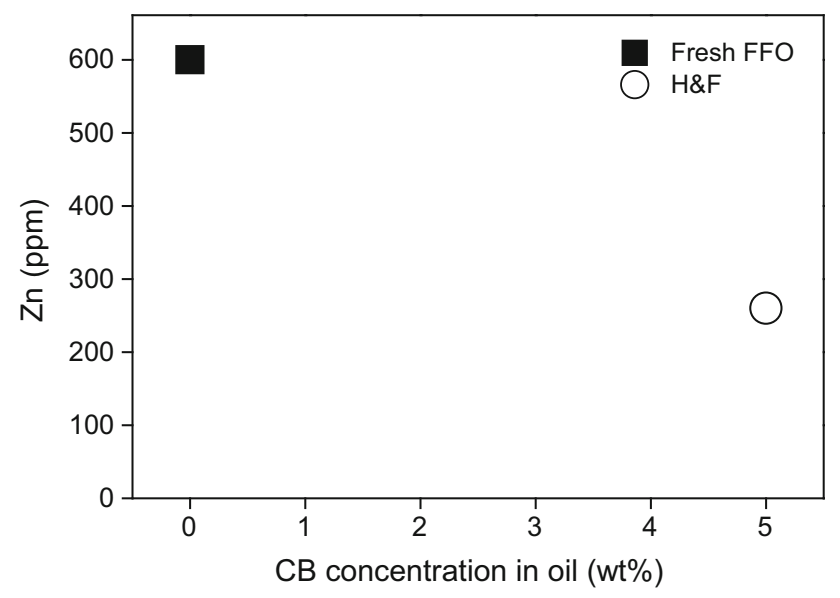

Fig. 11 Zinc concentration in fresh FFO and H\&F removed from the FFO as the oil still appeared dark in colour after filtering. It can be seen that filtering the oil reduced the wear obtained in comparison with FFO $+5 \mathrm{wt} \% \mathrm{CB}$. Although lower wear was observed in the H\&F sample, the wear was still much higher than that observed in FFO without CB (see Fig. 6). The higher wear in $\mathrm{H} \& \mathrm{~F}$ sample can be attributed to three factors such as (1) reduction in ZDDP concentration due to partial additive adsorption by $\mathrm{CB}$ particles, (2) abrasion by remaining $\mathrm{CB}$ particles, and (3) antagonistic interaction between remaining $\mathrm{CB}$ particles and the ZDDP additive.

In the H\&F sample, the $C B$ particles were mostly removed and ZDDP was still present, whereas ZDDP was not present in $\mathrm{BO}+5 \mathrm{wt} \% \mathrm{CB}+2 \mathrm{wt} \%$ disp, and the $\mathrm{CB}$ content was significantly higher. Despite these differences, the wear observed in the H\&F sample was similar to that observed in tests with $\mathrm{BO}+5 \mathrm{wt} \% \mathrm{CB}+2 \mathrm{wt} \%$ disp (see Fig. 11a). The high wear in $\mathrm{BO}+5 \mathrm{wt} \% \mathrm{CB}+2 \mathrm{wt} \%$ disp can be attributed to abrasion by $\mathrm{CB}$ particles, but similar high wear in $\mathrm{H} \& \mathrm{~F}$ sample cannot be justified by abrasion due to a significantly lower CB content. It is therefore unlikely that the first two factors presented above were responsible for the high wear observed in the $\mathrm{H} \& \mathrm{~F}$ sample. The authors thus believe that the antagonistic interaction between ZDDP and CB is the main factor that caused high wear in the H\&F sample. This antagonist interaction between ZDDP and CB results in what is known as corrosive-abrasive wear process which is discussed in detail in Sect. 3.4.3.

\subsubsection{Corrosive-Abrasive Wear}

As we have shown in the above sections, the high wear induced by $\mathrm{CB}$ in FFO cannot be simply explained by either abrasion or additive adsorption. Olomolehin et al.

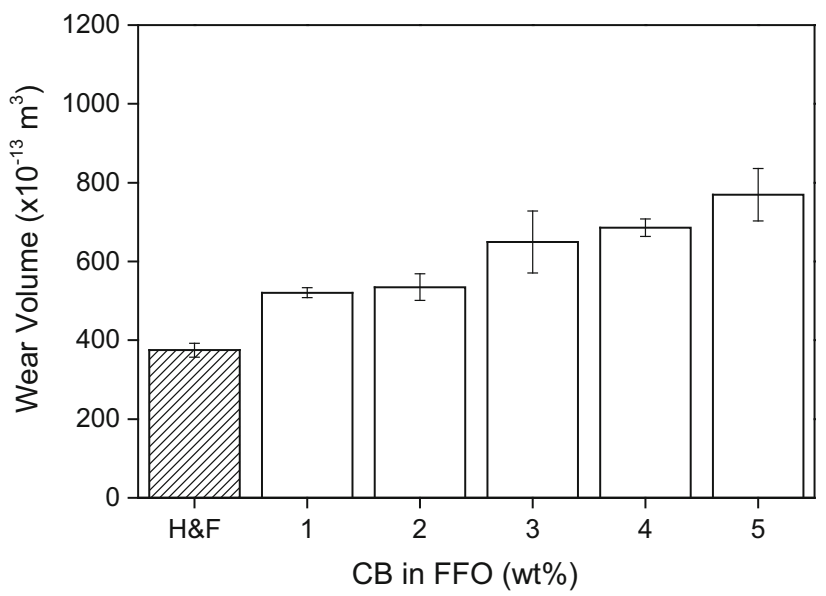

Fig. 12 Wear volume loss for tests conducted with $\mathrm{H} \& \mathrm{~F}$ and FFO containing various $\mathrm{CB}$ levels. Tests were conducted at $100{ }^{\circ} \mathrm{C}$ for $2 \mathrm{~h}$ 
[13] suggested that corrosive-abrasive wear process was responsible for high wear observed in oils containing phosphor-based additives when $\mathrm{CB}$ was present. In their study [13], it was shown that the combination of ZDDP with $\mathrm{CB}$ gave significantly higher wear than either ZDDP or $\mathrm{CB}$ alone. The authors also believe that this mechanism is likely to account for the exceptionally high wear observed with FFO containing CB since extremely high wear was only observed in FFO and not in BO.

According to the corrosive-abrasive wear mechanism, phosphorus-based tribofilms which are formed on the steel substrate are removed through abrasion by $\mathrm{CB}$ particles. Since the formation of the tribofilm involves intermixing of the substrate $(\mathrm{Fe})$ with the additive, the removal of the antiwear films also results in the removal of the substrate. A new tribofilm forms on the newly generated surface and is then removed by $\mathrm{CB}$ particles. The rapid tribofilm formation by the additives and removal by CB particles results in severe wear. This mechanism would explain the higher wear observed in FFO than in BO. This is because in BO, there are no antiwear tribofilms being continually formed and removed unlike in the case for FFO. Wear in tests with $\mathrm{BO}$ is due to the bore-polishing effect of the CB.

As mentioned above, in the corrosive-abrasive wear mechanism, there are two processes that occur simultaneously: tribofilm formation and tribofilm removal by $\mathrm{CB}$ particles. The rate of tribofilm formation would be determined by parameters such as temperature while the rate of tribofilm removal would be determined by $\mathrm{CB}$ content. The wear obtained is dictated by the rates of the two processes. It has been suggested that the rate of tribofilm formation is the rate-determining step in the corrosiveabrasive wear process. This means that high wear would be observed at higher temperatures and vice versa. However, there has been no experimental proof of this effect [13]. By analysing results obtained in this study at varying temperatures and $\mathrm{CB}$ content levels, it was possible to determine which process was the rate-determining step in the wear process.

Comparing wear results obtained at varying $\mathrm{CB}$ content levels and temperatures, it was observed that the effect of temperature on wear was more significant than the effect of CB content (see Fig. 6). These results indicate that the rate of tribofilm formation had a bigger impact on wear than the rate of tribofilm removal. Results from this study therefore confirm that the rate of tribofilm formation is indeed the rate-determining step in the corrosive-abrasive mechanism.

Results obtained from this study showed that at any given CB content level, significantly higher wear was observed at $100{ }^{\circ} \mathrm{C}$ than at $40{ }^{\circ} \mathrm{C}$ (Fig. 6). This observation can be explained by the fact that at higher temperatures, additive decomposition is faster and the surfaces are more reactive to additives. Thus, the rate of tribofilm formation is much higher at higher temperatures than at lower temperatures [31]. Consequently, the faster tribofilm replenishment at the higher temperature is quickly followed by tribofilm removal causing higher wear. At a given temperature, increasing the $\mathrm{CB}$ content level resulted in an increase in wear. The increase in wear can be attributed to the increase in the rate of tribofilm removal as the amount of abrasives at the contact increases.

\section{Conclusions}

This study was mainly focused on understanding the mechanisms by which CB contamination accelerates wear under boundary lubrication regime. Results from this study have demonstrated that abrasion and/or additive adsorption by $\mathrm{CB}$ do not sufficiently explain high wear in FFO containing CB. The authors believe that the corrosive-abrasive mechanism was responsible for the high wear observed in FFO when contaminated with $\mathrm{CB}$. When $\mathrm{CB}$ was present in oil containing phosphorus-based antiwear additives (ZDDP), the interaction of these additives with $\mathrm{CB}$ resulted in an antagonistic behaviour which enhanced wear. The corrosive-abrasive mechanism has been suggested before, although this was not proven experimentally. The novelty in this work was providing proof of the corrosive-abrasive mechanism by conducting tests at varying temperatures and CB content levels.

Open Access This article is distributed under the terms of the Creative Commons Attribution 4.0 International License (http://crea tivecommons.org/licenses/by/4.0/), which permits unrestricted use, distribution, and reproduction in any medium, provided you give appropriate credit to the original author(s) and the source, provide a link to the Creative Commons license, and indicate if changes were made.

\section{References}

1. Lattimore, T., Wang, C., Xu, H., Wyszynski, M.L., Shuai, S.: Investigation of EGR effect on combustion and PM emissions in a DISI engine. Appl. Energy 161, 256-267 (2016). doi:10.1016/j. apenergy.2015.09.080

2. Gautam, M., Chitoor, K., Durbha, M., Summers, J.C.: Effect of diesel soot contaminated oil on engine wear - investigation of novel oil formulations. Tribol. Int. 32(12), 687-699 (1999). doi:10.1016/S0301-679X(99)00081-X

3. Green, D.A., Lewis, R.: The effects of soot-contaminated engine oil on wear and friction: a review. Department of Mechanical Engineering, University of Sheffield, Sheffield (2008)

4. Hu, E., Hu, X., Liu, T., Fang, L., Dearn, K.D., Xu, H.: The role of soot particles in the tribological behavior of engine lubricating oils. Wear 304(1-2), 152-161 (2013). doi:10.1016/j.wear.2013. 05.002

5. Rounds, F.G.: Carbon: cause of diesel engine wear?. SAE Technical Paper 770829 (1977). doi:10.4271/770829 
6. Corso, S., Adamo, R.: The effect of diesel soot on reactivity of oil additives and valve train materials. SAE Paper (1984)

7. Rounds, F.G.: Soots from used diesel-engine oils: their effects on wear as measured in 4-ball wear tests. SAE Technical Paper 810499 (1981)

8. Skurai, T., Yoshida, K.: Tribological behaviour of dispersed phase systems. International Tribology Conference (1987)

9. Ryason, P.R., Chan, I.Y., Gilmore, J.T.: Polishing wear by soot. Wear 137(1), 15-24 (1990). doi:10.1016/0043-1648(90)90014-2

10. Ratoi, M., Castle, R.C., Bovington, C.H., Spikes, H.A.: The influence of soot and dispersant on ZDDP film thickness and friction. Lubr. Sci. 17, 25-43 (2004)

11. Nagai, I., Endo, H., Nakamura, H., Yano, H.: Soot and valve train wear in passenger car diesel engines. SAE Technical Paper 831757 (1983)

12. Torrance, M.: Wear of lubricated steel in the presence of dispersed carbon. In: Proceedings of the IMechE Mission of Tribology Conference, London, 2004. Professional Engineering Publishing Limited, London (2004)

13. Olomolehin, Y., Kapadia, R., Spikes, H.: Antagonistic interaction of antiwear additives and carbon black. Tribol. Lett. 37(1), 49-58 (2010). doi:10.1007/s11249-009-9489-4

14. Cadman, W., Johnson, J.H.: The study of the effect of exhaust gas recirculation on engine wear in a heavy-duty diesel engine using analytical ferrography. SAE Technical Paper 860378 (1986)

15. Liu, C., Nemoto, S., Ogano, S.: Effect of soot properties in diesel engine oils on frictional characteristics. Tribol. Trans. 46(1), 12-18 (2003). doi:10.1080/10402000308982593

16. Green, D.A., Lewis, R.: Effect of soot on oil properties and wear of engine components. J. Phys. D Appl. Phys. 40(18), 5488 (2007)

17. Chiñas-Castillo, F., Spikes, H.A.: The behavior of diluted sooted oils in lubricated contacts. Tribol. Lett. 16(4), 317-322 (2004). doi:10.1023/b:tril.0000015208.61698.01

18. Ramkumar, P., Wang, L., Harvey, T.J., Wood, R.J.K., Nelson, K., Yamaguchi, E., Harrison, J.J., Powrie, H.E.G.: The effect of diesel engine oil contamination on friction and wear. Paper presented at the World Tribology Congress, 3rd, WTC2005-63854 (2005)

19. Carraher, C.E.: Column: general topics. Polym News 29(4), 122-123 (2004). doi:10.1080/00323910490980895
20. Jao, T.C., Li, S., Yatsunami, K., Chen, S.J., Csontos, A.A., Howe, J.M.: Soot characterisation and diesel engine wear. Lubr. Sci. 16(2), 111-126 (2004). doi:10.1002/1s.3010160203

21. Watson, A., Valberg, P.: Carbon black and soot: two different substances. Am. Ind. Hyg. Assoc. J. 62, 218-228 (2001)

22. Guo, M.-F., Cai, Z.-B., Zhang, Z.-C., Zhu, M.-H.: Characterization and lubrication performance of diesel soot nanoparticles as oil lubricant additives. RSC. Advances 5(123), 101965-101974 (2015). doi:10.1039/c5ra19522e

23. Clague, A.D.H., Donnet, J.B., Wang, T.K., Peng, J.C.M.: A comparison of diesel engine soot with carbon black. Carbon 37(10), 1553-1565 (1999). doi:10.1016/S0008-6223(99)00035-4

24. Penchaliah, R., Harvey, T., Wood, R., Nelson, K., Powrie, H.: The effects of diesel contaminants on tribological performance on sliding steel on steel contacts. Proc Institution Mech Eng, Part J: J Eng Tribol 225(8), 779-797 (2011)

25. Berkani, S., Dassenoy, F., Minfray, C., Martin, J.-M., Cardon, H., Montagnac, G., Reynard, B.: Structural changes in tribo-stressed zinc polyphosphates. Tribol. Lett. 51(3), 489-498 (2013). doi:10. 1007/s11249-013-0188-9

26. Chiriu, D., Ricci, P.C., Polcaro, A., Braconi, P., Lanzi, D., Nadali, D.: Raman study on pompeii potteries: the role of calcium hydroxide on the surface treatment. J. Spectrosc 2014, 10 (2014). doi: $10.1155 / 2014 / 435026$

27. Kwon, T.Y., Fujishima, T., Imai, Y.: FT-Raman spectroscopy of calcium hydroxide medicament in root canals. Int. Endod. J. 37(7), 489-493 (2004). doi:10.1111/j.1365-2591.2004.00831.x

28. Zabinski, J.S., MacDevitt, N.T.: Raman spectra of inorganic compounds related to solid state tribochemical studies. In: USAF Wright Laboratory Report No. WL-TR-96-4034 (1996)

29. Morina, A., Neville, A., Priest, M., Green, J.H.: ZDDP and MoDTC interactions and their effect on tribological performance-Tribofilm characteristics and its evolution. Tribol. Lett. 24(3), 243-256 (2006)

30. Ardian, M., Anne, N.: Tribofilms: aspects of formation, stability and removal. J. Phys. D Appl. Phys. 40(18), 5476 (2007)

31. Gosvami, N.N., Bares, J.A., Mangolini, F., Konicek, A.R., Yablon, D.G., Carpick, R.W.: Mechanisms of antiwear tribofilm growth revealed in situ by single-asperity sliding contacts. Science 348(6230), 102-106 (2015) 